\title{
Benefits of robotic devices in medical rehabilitation of a case with neurofibromatosis type1
}

\author{
ANDRONIE-CIOARA Felicia Liana ${ }^{1}$, SERESS Daniela ${ }^{2}$, AVRAM GULER Natalia Loredana ${ }^{3}$, \\ CEVEI Iulia ${ }^{4}$, OPREA Claudia ${ }^{5}$, STOICANESCU Alexandra Maria ${ }^{4}$, JIMAN SCURT Laura Crina $^{3}$, \\ GHERLE Anamaria ${ }^{3}$
}

Corresponding author: ȘEREȘ Daniela E-mail: bala.daniella@yahoo.com

Balneo Research Journal

DOI: http://dx.doi.org/10.12680/balneo.2020.407 Vol.11, No.4, December 2020

1 Department of Psychoneurosciences and Rehabilitation, Faculty of Medicine \& Pharmacy, University of Oradea, Romania 2 Cluj Napoca County Emergency Hospital, Department of Neurology, Cluj-Napoca, Romania 3 Medical Rehabilitation Clinical Hospital Baile Felix, Romania 4 University of Medicine and Pharmacy "Victor Babes", Timisoara, Romania 5 County Emergency Clinical Hospital Timisoara, Department of Pediatrics, Romania

\begin{abstract}
The term neurofibromatosis (NF) describes a group of genetic disorders that primarily affect the cell growth of neural tissues. Three clinically and genetically distinct forms of neurofibromatosis have been described: neurofibromatosis type 1 (NF1), neurofibromatosis type 2 (NF2) and schwannomatosis. The inheritance pattern is autosomal dominant for all three types. We present the case of a 57 years old man, admitted to the Medical Rehabilitation Clinical Hospital Baile Felix, Romania, who was diagnosed with spastic tetraparesis, neurofibromatosis type 1, chronic viral hepatitis B and D, hypercholesterolemia, sarcopenia and osteoporosis. The objectives of the rehabilitation treatment were combating pain; preventing and correcting vicious postures at rest and during activity; maintaining or increasing joint mobility; increasing the mobility of the cervical and lumbar spine; decreasing spasticity; increasing strength of paralyzed muscles; improving motor control of paralyzed limbs; transfers reeducation, gait re-education; improving breathing; improving ADLs; maintaining autonomy; gaining daily independence; prevention of recurrent complications and increasing the quality of life. The rehabilitation treatment was complex, performed over a period of 2 weeks and included various physiotherapy approaches, hydrokinetotherapy, massage, occupational therapy, robotic devices and virtual reality. It improved the patient's functional independence and quality of life. Innovations in information technology will refine and increase the efficiency, expertise and competence of medical rehabilitation, in order to ensure comfort for the patient and an appropriate and safe therapeutic approach.
\end{abstract}

Keywords: neurofibromatosis, robotic devices, medical rehabilitation,

\section{Introduction}

\section{Key clinical message}

Neurofibromatosis is a serious condition that can lead to tetraparesis from the rapidly growth of neurofibromas, which cause cervical spinal compression, therefore a combined neurosurgical and medical rehabilitation early approach may improve the outcome and long term quality of life in patients with NF1.

\section{Introduction}

The term neurofibromatosis (NF) describes a group of genetic disorders that primarily affect the cell growth of neural tissues (1). Three clinically and genetically distinct forms of neurofibromatosis have been described: neurofibromatosis type 1 (NF1), neurofibromatosis type 2 (NF2) and schwannomatosis. The inheritance pattern is autosomal dominant for all three types (2).

NF1, also called von Recklinghausen disease, is caused by pathogenic mutations of the NF1 gene, which is located on chromosome 17q11.2 (3). The disease is characterized by specific clinical features including hyperpigmented spots, neurofibromas, Lisch nodules, skeletal abnormalities and increased risk to malignancies, the effects of the mutant gene extending on multiple systems of the body. Neurofibromas can develop from dorsal nerve roots, as well as peripheral nerves in the spinal canal. Spinal tumors were observed in about $40 \%$ of patients. Spinal cord involvement in neurofibromatosis is typically from extramedullary growth of spinal nerve root tumors. The management of spinal neurofibromas consists of careful observation and surgery for the most severe cases, depending on the anatomical location, degree of invasion and risk of recurrence at the surgical site (4).

The purpose of this report is to present a case of spinal neurofibromatosis focusing on usage of robotic devises in rehabilitation management.

\section{Case presentation}

We present the case of a 57 years old male, admitted to the Medical Rehabilitation Clinical Hospital Baile Felix, Romania based on the following symptoms: orthostatism and gait deficiency, accentuated tetramelic motor deficit, sensitive deficit, sphincter dysfunction, multiple joints stiffness, neck pain, major functional deficit, activities of daily living(ADL) disability. The patient's family history revealed that his father had Von Recklinghausen's disease, but it was not medically documented. From the patient's past medical history we found that the current disease had an insidious onset, at the age of 28, in 1990, with low back pain, severe stiffness and balance disorder. He was diagnosed in 1993 with NF type 1, while developing intrarachidian neurofibroma (C1-C2, C3-C4, C4-C5), which caused medullary compression. He was operated in 1993: C3-C4 laminectomy with subtotal macroscopic ablation of 3 left antero-lateral tumors extended to the 
base of the skull. In 1997 he underwent surgery due to the aggravation of the motor deficit, tetraparesis, hypoesthesia in the right leg, pyramidal syndrome and sphincter dysfunction. The extension of laminectomy to $\mathrm{C} 3$ with scar excision was performed. On September 2003 the patient was admitted again into the neurosurgical department with worsening of symptoms and the excision of the scar was performed once again. A contrast MRI of the dorsal spine performed in 2015 showed multiple neurofibromas along the cervical and dorsal nerves, with stenosis of the cervical spinal canal and medullary and bulbar compression. In 2017 he was admitted again into the neurosurgical department with progressive tetraparesis and gait deficiency, he underwent microscopic ablation of the tumor formation from root level $\mathrm{C} 2$ through posterior cervical approach. He also reported having pulmonary neurofibroma, bilateral neurosensory hearing loss, uncomplicated sigmoid diverticulosis.

The general physical examination revelead asthenic constitution, over 6 café-au-lait spots on the trunk and extremities, skinfold freckling, laterocervical and posterior cervical postoperative keloid scar, cervical spine hypomobility and urgent urination. The musculoskeletal system evaluation revealed: ambulation in a wheelchair over short distances, could not maintain orthostatism, bilateral "claw" hand, incomplete left eyelid ptosis, left miosis, left enophthalmia (Claude-Bernard-Horner syndrome), dorsal paravertebral tumors, fasciculations in the right pectoralis muscle and in the deltoid muscle bilaterally, in the biceps brachii, triceps brachii and suprascapular muscles bilaterally, bilateral sternocleidomastoid muscles atrophy. Muscle strength was $4 / 5$ in the both upper limbs, and $3 / 5$ in both lower limbs. Evaluation of muscle spasticity on the Modified Ashworth Scale revealed 1 for the upper limbs and 3 for the lower limbs. Other findings were: hammer toes; pyramidal syndrome; tibio-tarsal and bilateral radio-carpal joint stiffness; bilateral lower limb exteroceptive hypoaesthesia; extended muscle atrophies of the chest muscles, deltoid muscle, biceps and triceps muscles and brachial suprascapular muscle; bladder incontinence through overflow, urgent urination. Laboratory findings showed high level of serum amylase and hypercholesterolemia.

The cervical spine radiography showed: reversal of the profile curve with anterolisthesis $\mathrm{C} 4 \mathrm{gr}$. I $(5 \mathrm{~mm})$ and $\mathrm{C} 5$ preanterolisthesis and advanced inferior cervical dysarthrosis; metal clips in right paravertebral projection C6. Bilateral ankle radiography revealed incipient tarsaltibial osteoarthritis.

Determination of the bone mineral density by osteodensitometry showed a lumbar spine $Z$ score of -1.7 , right hip $\mathrm{Z}$ score was -2.4 and left hip $\mathrm{Z}$ score was -2.1 . Total lean body mass was 0.54 .
His diagnoses were: Spastic tetraparesis (neurological injury Asia C motor level C5). Neurofibromatosis type 1 (C1-C2, C3-C4 intrarachidian neurofibroma, operated, recurrent, re-operated). Chronic viral hepatitis B and D. Hypercholesterolemia. Sarcopenia. Osteoporosis.

The treatment strategies included medical treatment: hypocholesterolemic dietary regime; nootropic medication, antioxidant medication, psychoaffective support medication, epilepsy prophylaxis, and medical rehabilitation.

The objectives of rehabilitation treatment were combating pain; preventing and correcting vicious postures at rest and during activity; maintaining or increasing joint mobility; increasing the mobility of the cervical and lumbar spine; decreasing spasticity; increasing strength of paralyzed muscles; improving motor control of paralyzed limbs; transfers re-education, gait re-education; improving breathing; improving ADLs; maintaining autonomy; gaining daily independence; prevention of recurrent complications (constipation, epileptic seizures, risk of fractures, urinary tract infections) and increasing the quality of life.

The rehabilitation treatment was complex, performed over a period of 2 weeks and included various physiotherapy approaches: hydrokinetotherapy in the pool: $36^{\circ} \mathrm{C}, 20$ minutes daily; massage; occupational therapy; robotic devices; virtual reality.

In order to decrease spasticity, neuroproprioceptive facilitation techniques were recommended: slow and sustained muscle stretching, rhythmic initiation, slow reversals with opposition.

To increase muscle strength in the upper limbs isometric and isotonic resistance active movements were recommended, and for the lower limbs assisted active movements for performing the entire movement trip, then manual resistance movements, isometric exercises for toning the pelvic girdle.

Re-education of wheelchair transfers was made using specific techniques. Bobath ball was used for balance and coordination; gait re-education used the treadmill in straight and inclined plane.

To improve the respiratory amplitude, specific exercises were recommended for toning the diaphragm and the thoracic muscles with the aid of small weights, then with gradual increasing of the weight.

Occupational therapy had the following objectives and means: prevention of deformities and vicious postures caused by changes in muscle tone, by using orthotics in daily life; inhibition of abnormal movement and posture patterns; restoring active mobility, strength and coordination in the upper body; acquiring a maximum degree of functional independence in self-care; facilitating family reintegration by assigning occupational roles appropriate to current abilities; establishing a balance between rest, lucrative and recreational activities; 
improving ADLs and increasing the quality of life by optimizing the patient's home environment to his individual abilities.

Robotic-assisted gait training using the Lokomat ${ }^{\circledR}$ stimulated neuroplasticity by the intensely repetitive movements, associated with visual, auditory and tactile feedback. Lokomat patient report revealed that the patient improved motor control, proven by increasing of speed by $58 \%$ (fig. 1) and patient's personal contribution to gait increased by $3 \%$ (fig. 2). Robotic assistance of Reo-Go and Hand of Hope devices were used in upper limb reeducation, by using passive movements (flexibility, mobility, reduction of spasticity), or by assisting an active movement (the patient has active mobility but not at full range of motion).

The patient benefited from two projective virtual reality systems, one called "Nirvana" (which also includes a diagnostic and testing system) and a desktop type included in robotic gait therapy (Lokomat).

By the end of the second week of complex rehabilitation, the patient had improvements in muscle strength, coordination and balance, and reeducation of transfers.

To assess the degree of disability and the progress the patient made during rehabilitation we used the FIM scale. FIM scores were tracked on admission in and discharge from our hospital, and it was 43 and 56, respectively.

Psychological therapy performed cognitive assessment, memory and concentration tests, psychological adjustment of the patient in order to accept his deficiency, to improve communication capacity and facilitate social integration.

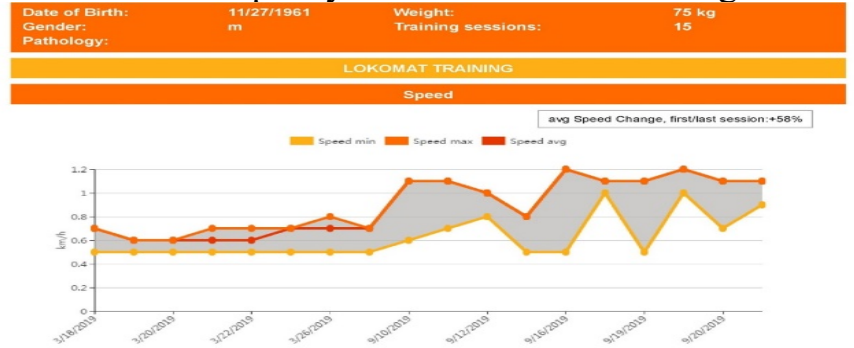

Fig. 1. Lokomat training revealing a significant average speed increase between the first and the last session

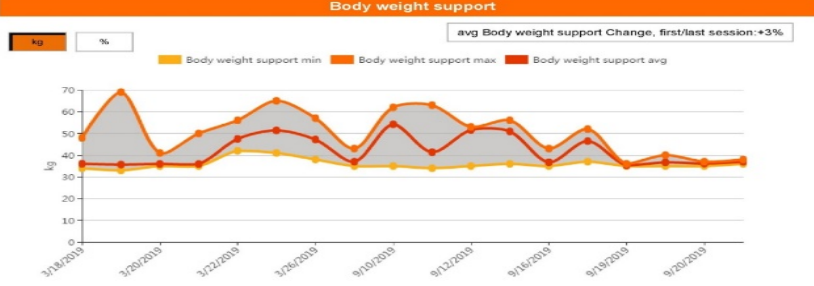

Fig. 2. Lokomat training revealing an increase of average body weight support between the first and the last session The patient gave written informed consent for publication of the case. The study was performed in accordance with the Declaration of Helsinki.

\section{Discussion}

Neurofibromatoses are inherited tumor predisposition syndromes that are characterized by benign neurofibromas and an increased risk of malignant peripheral nerve sheath tumors and connective tissue malignancies (5). Another characteristic is highly variable clinical expressivity, some individuals having barely noticeable neurological problems, while others are severely affected (6). NF1 or von Recklinghausen's disease (named after the German pathologist, Friedrich Daniel von Recklinghausen who described the disease in 1882) is the most common type and manifests at birth or during early childhood. Neurofibroma is a benign peripheral nerve sheath tumor which arises from Schwann cells and peripheral fibroblasts and constitute one of the main manifestations of NF1 (1). They are rarely present at birth and usually appear in late childhood or early adolescence (7). Enlargement and deformity of bones and curvature of the spine (scoliosis) may also be present. On occasion, people with NF1 may develop tumors in the brain, on the cranial nerves or involving the spinal cord. Inguinal and axillary freckles are frequently present (8).

The patient described here is a very typical case of NF-1, with multiple café-au-lait spots on the trunk and arms and neurofibromas. The particularity of this case is the presence of multiple recurrent neurofibromas localized at the cervico-dorsal level of the spine and of a plexiform neurofibroma (PN) localized on the posterior wall of the left thorax with intrathoracic extension. The investigation of this case was complex, in order to exclude other tumors (9). Plexiform neurofibromas (PNs) represent an uncommon variant of NF1. They can occur at any age. Neurofibromas emerge from multiple nerves as bulging and deforming masses, and involve also connective tissue and skin folds (10). Studies of Tonsgard et al. (11) and Schorry et al. (12) performed on 126 and 240 individuals with NF1, respectively, have shown the frequency of PNs and their most common sites. Most of the patients in these two studies were asymptomatic.

Sarcopenia was added to the motor deficit, further reducing the patient's quality of life $(13,14)$. In the neurological patient the presence of neck pain and lowback pain increases disability, requiring special investigations and adjustment of the rehabilitation treatment $(15,16)$.

The case management required a multidisciplinary team (17). Prevention of the risk of falling is an important goal in this patient with motor deficit and low bone mineral density (18). There is no medical treatment for NF1, therefore the management must be toward prevention and control of the complications. The rate of malignant transformation of NF1 is low $(3-5 \%)$, but these malignancies can cause other clinical problems, including esthetic and functional compromising. Unfortunately, sometimes surgical excision cannot completely remove large or multiple lesions (1). Surgical intervention is indicated when the patient's function is impaired. In this case, the patient had had four operations, but the lesions 
recurred and because of the extent of the lesions, he had Claude Bernard syndrome. Post-surgery regrowth is also common, as observed in our case.

Our patient had significant motor deficits, such as reduced muscle mass, muscle weakness, fatigability, marked spasticity, with a progressive course over the years. These are recognized as common manifestations of NF1, and have been attributed to central nervous system dysfunction (19). However, recent preclinical and clinical studies have indicated a primary role for the NF1 gene product, neurofibromin, in muscle growth and metabolism (20).

Repeated patterns of movement are an important factor conditioning the neuroplasticity of the human nervous system. Robotic neurorehabilitation devices have been developed precisely to enable repetitive motor training of patients with important deficits. In this case, the main purpose of the treatment was to improve independence, mobility, and performing activities of daily living. This is usually achieved with physical and occupational therapy, but in our case we also used robotic devices and virtual reality. One of these devices is Lokomat, an adjustable exoskeleton combined with a treadmill that ensures physiologic gait pattern assistance by mobilizing the patient's lower limbs that cannot move without support, detecting the patient's active contribution to limb mobilization, automatically adjusting throughout the treatment session, balancing patient support and participation. This device is able to deliver high amounts of repetitions in a single therapy session, thus the patient will not be tired. It is also increasingly motivational by applying audio-visual displays and games scenarios and can provide variable practice schedules at arbitrary frequencies. The device measures the patient's effort and challenges him accordingly, allowing the therapist to adjust the difficulty of the training according to the patient's motor skills. The Lokomat device can help patients with spinal cord injuries or paralyzed by stroke learn to walk again. Lokomat provides what is known as automated locomotion therapy. Its benefits have been mentioned in various studies (21-23).

Robotic assistance of Reo-Go, a device used in upper limb reeducation through its screen, allows a feedback process in which the patient is constantly informed about the amplitude and intensity of the performed movement. It increased motivation through functional exercises and entertaining games for patient, improving arm function, patient's well-being and independence, and trained activities of daily living. The device stimulates the cerebral cortex and allows the restoration of functional structures and the neighboring structures, unaffected by the disease.

Hand of Hope is a device used also in upper limb reeducation. The robotic hand reeducation device has beneficial results in reeducating the functional deficit of the neurological hand and gaining emotional support by interacting with the information on the computer screen. Our patient has a claw hand deformity that we tried to reduce by using the device that takes over the activity of the hand and each finger through the external help provided. It completed the physical and occupational therapy, facilitating daily activity by using passive movements, which maintain flexibility, mobility, and at the same time, reduces spasticity (24-26).

Virtual reality is an assistive device used for both upper and lower body training, through a computer assisted rehabilitation environment in which the patient interacts within the virtual environment, performing functional or game-like tasks of varying levels and difficulty. This enables the therapist to determine the optimal environmental factors for the patient. Within the "interaction space" sensations and perceptions related to the virtual experience take place: here the patient's sense of presence is established, and the process of assigning meaning to the virtual experience and the actual performance of virtual tasks or activities occur. Creating goals in the virtual world that reproduce real life ensures relearning and re-gaining skills and lost physical functions, and it also increases the success rate of rehabilitation programs that use the complexity of virtual reality $(27,28)$.

Occupational therapy is an important part of the rehabilitation process. It allows patients to be more social, to use their own functions for creative jobs and to deal with psychological problems like depression (29).

As for other genetic conditions, the NF1 patients require genetic counseling and in specific cases mutation detection can be performed using different molecular methods (30-32). NF1 patients should be advised that the disorder is autosomal dominant and that the recurrence risk is $50 \%$ in both sexes. It is important to conduct a longterm follow-up, because of local complications and the risk of malignant transformation. In cases with a rapid increase in the size of neurofibroma and presence of pain, the probability of malignant transformation must be considered (1).

Conclusions: The complex medical rehabilitation, which included upper and lower limb training robotic devices, improved the patient's functional independence and quality of life. Virtual reality techniques are being developed in the field of medical rehabilitation. The possibilities, approaches and solutions in virtual realitybased applications are huge. Innovations in information technology will refine and increase the efficiency, expertise and competence of medical rehabilitation, in order to ensure comfort for the patient and an appropriate and safe therapeutic approach. 


\section{References:}

1. Ghalayani P, Saberi Z, Sardari F. Neurofibromatosis type I (von Recklinghausen's disease): A family case report and literature review. Dent Res J (Isfahan). 2012 Jul;9(4):483-488.

2. Korf BR. Neurofibromatosis. Handb Clin Neurol. 2013 Apr;111:333-340.

3. Gutmann DH, Ferner RE, Listernick RH, Korf BR, Wolters PL et al. Neurofibromatosis type 1. Nat Rev Dis Primers. 2017 Feb;3:17004.

4. Carman Kb, Yakut A, Anlar B, Ayter S. Spinal neurofibromatosis associated with classical neurofibromatosis type 1: genetic characterisation of an atypical case. BMJ Case Rep. 2013 Feb 14;2013:bcr2012008468.

5. Seminog OO, Goldacre MJ. Risk of benign tumours of nervous system, and of malignant neoplasms, in people with neurofibromatosis: population-based record-linkage study. Br J Cancer. 2013 Jan;108(1):193-198.

6. Sabbagh A, Pasmant E, Laurendeau I, Parfait B, Barbarot S et al. Unravelling the genetic basis of variable clinical expression in neurofibromatosis 1. Hum Mol Genet. 2009 Aug;18(15):2768-2778.

7. Cunha KS, Barboza EP, Dias EP, Oliveira FM. Neurofibromatosis type I with periodontal manifestation. A case report and literature review. $\mathrm{Br}$ Dent J. 2004 Apr;196(8):457-60.

8. Stoicanescu LD, Cevei ML, Sirbu EM, Zdrinca MM, Mutiu G. Unusual occurrence of avascular necrosis with bilateral involvement and ankylosing spondylitis, meningioma and Hodgkin lymphoma. Rom J Morphol Embryol. 2019 JulSept:60(3):1003-1007.

9. Tchernev G, Chokoeva AA, Patterson JW, Bakardzhiev I, Wollina U et al. Plexiform Neurofibroma: A Case Report. Medicine (Baltimore). 2016 Feb;95(6):e2663.

10. Tonsgard JH, Kwak SM, Short MP, Dachman AH. CT imaging in adults with neurofibromatosis-1. Frequent asymptomatic plexiform lesions. Neurology. 1998 Jun;50(6):1755-60.

11. Schorry EK, Crawford AH, Egelhoff JC, Lovell AM, Saal HM. Thoracic tumors in children with neurofibromatosis 1. Am J Med Genet. 1997 Sept;74(5):533- 537.

12. Cevei M, Onofrei RR, Cioara F, Stoicanescu D. Correlations between the Quality of Life Domains and Clinical Variables in Sarcopenic Osteoporotic Postmenopausal Women. J. Clin. Med. $2020 \mathrm{Feb} ; 9(2): 441$

13. Hodinka L, Vereckei E, Gasparik AI. Sarcopenia és életminőség: a Sarcopenia Quality of Life (SarQoL) kérdőív hiteles magyar fordítása [Sarcopenia and quality of life: the validated Hungarian translation of the Sarcopenia Quality of Life (SarQoL) questionnaire]. Orv Hetil. 2018 Sep;159(36):1483-1486.

14. Sirbu E, Onofrei R, Szasz S, Susan M. Predictors of disability in patients with chronic low back pain. Archives of Medical Science. 2020 Jul. https://doi.org/10.5114/aoms.2020.97057

15. Cevei M, .Roșca E, Lazar L, Muţiu G, Stoicănescu D et al. Imagistic and histopathologic concordances in degenerative lesions of intervertebral disks. Rom J Morphol Embryol. 2011 Jan-March; 52 (1 Suppl):327-332.

16. Roman N, Tirziman E, Sorea D, Miclaus R, Repanovici A et al. Ethical Dilemmas in the Interdisciplinary Approach to Informed Consent to Patients in Physiotherapy Services in Romania. Revista de Cercetare si Interventie Sociala. 2018 Dec;63:290-303.

17. Moga M, Preda G, Marceanu L, Miclaus R, Bagiu N. Lifestyle factors related to bone mineral density in postmenopausal women. Journal of Environmental Protection and Ecology. 2008;1(1):67-69.

18. Feldmann R, Denecke J, Grenzebach M, Schuierer G, Weglage J. Neurofibromatosis type 1: motor and cognitive function and T2-weighted MRI hyperintensities. Neurology. 2003 Dec;61(12):1725-1728.

19. Summers MA, Quinlan KG, Payne JM, Little DG, North KN et al. Skeletal muscle and motor deficits in Neurofibromatosis Type 1. J Musculoskelet Neuronal Interact. 2015 Jun;15(2):161-170.

20. Nam KY, Kim HJ, Kwon BS, Park JW, Lee HJ et al. Robotassisted gait training (Lokomat) improves walking function and activity in people with spinal cord injury: a systematic review. J Neuroeng Rehabil. 2017 Mar;14(1):24.

21. van Kammen K, Boonstra AM, van der Woude LHV, Visscher C, Reinders-Messelink HA et al. Lokomat guided gait in hemiparetic stroke patients: the effects of training parameters on muscle activity and temporal symmetry. Disabil Rehabil. 2020 Oct;42(21):2977-2985.

22. van Silfhout L, Váňa Z, Pětioký J, Edwards MJR, Bartels RHMA et al. Highest ambulatory speed using Lokomat gait training for individuals with a motor-complete spinal cord injury: a clinical pilot study. Acta Neurochir (Wien). 2020 Apr;162(4):951-956.

23. Casadio M. Giannoni P. Morasso P. Sanguineti V. A proof of concept study for the integration of robot therapy with physiotherapy în the treatment of stroke patients. Clin Rehabil. 2009 Mar;23(3):217-228.

24. Krebs HI, Krams M, Agrafiotis DK, DiBernardo A, Chavez JC et al. Robotic measurement of arm movements after stroke establishes biomarkers of motor recovery. Stroke. 2014 Jan;45(1):200-204.

25. Miller EL, Murray L, Richards L, Zorowitz RD, Bakas T et al. Comprehensive overview of nursing and interdisciplinary rehabilitation care of the stroke patient: a scientific statement from the American heart association. Stroke. 2010 Oct;41(10):2402-2448.

26. Kizony R, Katz N, Weiss PL. Virtual reality based intervention in rehabilitation: relationship between motor and cognitive abilities and performance within virtual environments for patients with stroke. Proc 5th Int Conf Disability, Virtual Reality and Assoc. Tech. Oxford, UK. 2004:19-26.

27. Maggio MG, Torrisi M, Buda A, De Luca R, Piazzitta D et al. Effects of robotic neurorehabilitation through lokomat plus virtual reality on cognitive function in patients with traumatic brain injury: A retrospective case-control study. Int J Neurosci. 2020 Feb;130(2):117-123.

28. Nas K, Yazmalar L, Şah V, Aydın A, Öneş K. Rehabilitation of spinal cord injuries. World J Orthop. 2015 Jan;6(1):8-16.

29. Ly KI, Blakeley JO. The Diagnosis and Management of Neurofibromatosis Type 1. Med Clin North Am. 2019 Nov;103(6):1035-1054.

30. Gug C, Stoicanescu D, Mozos I, Nussbaum L, Cevei M et al. De Novo 8 p21.3 $\rightarrow$ p23.3 Duplication with $t(4 ; 8)(q 35 ; p 21.3)$ Translocation associated with Mental Retardation, Autism Spectrum Disorder and Congenital Heart Defects: Case Report With Literature Review. Front. Pediatr. 2020 Jul; 8:375.

31. Gug C, Gorduza EV, Lăcătuşu A, Vaida MA, Bîrsăşteanu F et al: CHARGE syndrome associated with de novo (I1460Rfs*15) frameshift mutation of CHD7 gene in a patient with arteria lusoria and horseshoe kidney. Exp Ther Med. 2020 Jul;20:479485.00 